\title{
Land Use-Transportation Modeling with UrbanSim: Experiences and Progress
}

\author{
Introduction to the Special Issue
}

\author{
Daniel Felsenstein \\ Kay Axhausen \\ Paul Waddell \\ Hebrew University of Jerusalem ${ }^{\text {a }}$ \\ ETH Zürich ${ }^{\text {b }}$ \\ University of California, Berkeley ${ }^{c}$
}

While UrbanSim ostensibly continues a microsimulation tradition in land-use transportation modeling extending the work of Wegener (1982), Mackett (1990), and Simmonds (2001), it has also generated a veritable mini-revolution of its own.

As an open source and modular software system, using highly disaggregated data for dynamic simulation it has been instrumental in making integrated land-use transportation modeling accessible beyond the bespoke models that characterized earlier generations. The UrbanSim model and the collaborative OPUS framework (Open Platform for Urban Simulation) that it has spawned have stimulated much original progress in this field.

The object of this thematic issue of JTLU is to report on this work and to illustrate the various ways UrbanSim has been adapted. However, this special issue is more than just a collection of progress reports. A central theme running through all the papers is that integrated landuse-transportation modeling in Europe presents a series of challenges and demands not necessarily present in the United States context in which UrbanSim was developed. Thus, while the UrbanSim system can be technically adapted to European studies given the data and resources, the prevailing land-use transportation environment in Europe differs from the United States.

This is expressed in many ways. First, a very different land use environment exists in Europe. This makes for greater government regulatory controls over urban development at all levels. Second, a very different attitude exists in European cities towards car ownership and dependence on public transport. Third, Europe has a very distinctive ethos with respect to respect to housing tenure and property rights. This results in levels of home-ownership, composition of housing stocks and 'acceptable' patterns of residential density, very different from those prevailing in the United States. Fourth, the major United States urban land-use issue, that of residential sprawl, features much less prominently in Europe where commercial (or employmentdriven) sprawl is high on the urban agenda. A consequence of this relates to the reverse side of the urban coin: the city center. European city centers have higher levels of residential land use, more mixed land uses and in general greater household presence than North American city centers characterized (and perhaps caricatured) by urban blight and social tension. Finally, movement in European cities is also very different. The lack of a Tiebout-style adjustment mechanism in Europe whereby people move to gain better access to public goods, makes for lower mobility rates.

\footnotetext{
amsdfels@mscc.huji.ac.il

baxhausen@ivt.baug.ethz.ch

${ }^{c}$ waddell@berkeley.edu
} 
The paper by Waddell, Wang, Charlton, and Olsen describes the UrbanSim-OPUS platform for land-use-transportation modeling in the context of a model for San Francisco. The paper includes many state of the art advances that can act as a benchmark for further UrbanSim modeling. Among these we note the use of parcel and building data instead of gridcells and integration of the land use simulation model with an activity based transportation model rather than the conventional trip based travel demand model.

Data issues present a major challenge in any modeling effort and UrbanSim is no exception. Various papers in this collection present novel approaches, many of them stemming from the paucity of disaggregated data in Europe, in comparison to the United States. The paper by Patterson, Kryvobokov, Marchal, and Bierlaire illustrates the use of data aggregation in the application of urbanism modeling in two similar-sized European contexts, Brussels and Lyons. In the former, data disaggregation was used in order derive gridcell values from zones. In the latter, aggregate data were applied directly to the travel zones with zonal data taken as representing gridcells. The Rome paper (di Zio, Montanari, and Staniscia) illustrates the use of interpolation techniques in order to deal with data constraints relating to both travel time accessibility and land values in UrbanSim. Löchl and Axhausen show the paucity of land price data that plagues much land use simulation modeling can be side-stepped, using hedonic regression in an UrbanSim application for Zurich.

Other papers deal with adaptation and extension of the individual behavioral models in UrbanSim. The Tel Aviv paper (Felsenstein and Ashbel) presents an attempt at textbook application of the basic UrbanSim model with one cardinal change; accounting for the endogeneity of prices in the relationship between land developers and the land price market. In the Zurich case, the use of different estimation techniques for estimating neighborhood and spillover effects in the land price model, is illustrated. This presents a natural extension of individual model estimation into the realm of spatial statistics.

The initial gestation for many of the papers presented here was an informal European UrbanSim Users group meeting organized by Kay Axhausen at ETH, Zurich in 2008. All of the papers published herein have been subjected to rigorous peer review.

\section{References}

di Zio, S., A. Montanari, and B. Staniscia. 2010. Simulation of urban development in the City of Rome: Framework, methodology, and problem solving. The Journal of Transport and Land Use, 3(2):85-105. doi: 10.5198/jtlu.v3i2.154.

Felsenstein, D. and E. Ashbel. 2010. Simultaneous modeling of developer behavior and land prices in urbansim. The Journal of Transport and Land Use, 3(2):107-127. doi: 10.5198/jtlu.v3i2.175.

Löchl, M. and K. W. Axhausen. 2010. Modeling hedonic residential rents for land use and transport simulation while considering spatial effects. The Journal of Transport and Land Use, 3(2):39-63. doi: 10.5198/jtlu.v3i2.117.

Mackett, R. 1990. The systematic application of the LILT model to Dortmund, Leeds and Tokyo. Transportation Reviews, 10:323-338.

Patterson, Z., M. Kryvobokov, F. Marchal, and M. Bierlaire. 2010. Disaggregate models with aggregate data: Two UrbanSim applications. The Journal of Transport and Land Use, 3(2):5-37. doi: 10.5198/jtlu.v3i2.113. 
Simmonds, D. 2001. The objectives and design of a new land use modelling package: DELTA. In D. Clarke and M. Madden, eds., Regional Science in Business, pp. 159-188. Berlin: Springer.

Waddell, P., L. Wang, B. Charlton, and A. Olsen. 2010. Microsimulating parcel-level land use and activity-based travel. The Journal of Transport and Land Use, 3(2):65-84. doi: 10.5198/jtlu.v3i2.124.

Wegener, M. 1982. Modeling urban decline: A multilevel economic-demographic model for the Dortmund region. International Regional Science Review, 7(2):217-241. 